Fisheries; and, while the question was being considered by the Canadian Government, a start at actual research was made with the co-operation of the Submarine Signal Company of Boston, Mass., U.S.A. It was decided to repeat the experiments of Prof. R. A. Fessenden (Trans. Am. Inst. of Elect. Eng., vol. 33, Oct. r9I4, pp. I 569-I 58r) "On Obtaining the Depth of the Sea by the Echo Method." A Fessenden oscillator with the associated motor generator set was installed on the Canadian hydrographic survey ship Cartier, and during the month of October I9I 5 , numerous experiments were tried on " depth sounding" (Fig. I). A short experience showed that for moderate depths, 30 to 40 fathoms, the same oscillator could not be used for receiving the echo, on account of the persistence of transients in the electromagnetic circuits. A separate hydrophone, shielded from the oscillator signal by being placed on the opposite side of the ship, was therefore employed, and experiments, though for the most part unsuccessful on account of the weak echoes received from a sea bottom of soft ooze and clay, gave indications at favourable localities as to the ultimate possibilities of this method.

At this early date and under war conditions, it was practically impossible to obtain thermionic amplifiers

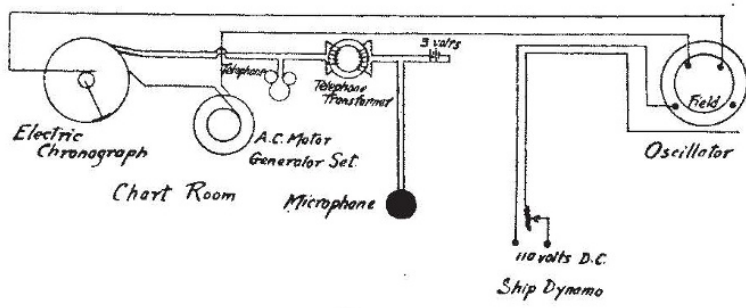

FIG. 1.

by means of which echo signals could be received. Then, too, for the faint echoes involved, the type of hydrophone available was not sufficiently sensitive, while for experimental work the type of oscillator available, weighing $1300 \mathrm{lb}$, was inconvenient for overboard use, especially with the ship in motion.

In a report submitted to the Electrical and Submarine Committee of the Admiralty Inventions Board, it was finally concluded that special transmitters of less weight, designed for inboard use, would have to be developed in conjunction with a more sensitive type of hydrophone. In order to obviate the use of thermionic amplifiers as much as possible, it was decided to make use of a hydrophone, suitably damped, capable of tuning in to the definite wave-length emitted.

A tuneable diaphragm, forming an essential feature of a hydrophone, was briefly described in the Proc.

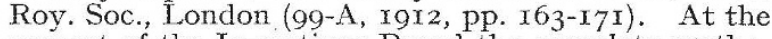
request of the Inventions Board the complete mathematical theory of electrically operated sound generator was undertaken, with the view of facilitating design.

It will be readily seen that a diaphragm both for emitting and receiving corresponds to the aerial in radio-telegraphy. In the latter field, the enormous advantage of the aerial tuning condenser for the selection of narrow wave-length bands is the characteristic feature of modern radio transmission and reception, an enormous increase in the range of communication having thus been effected. In just the same way, the writer anticipates a radical improvement in the art of submarine signalling by the introduction of tuneable diaphragms enabling specified wave-lengths to be picked up to the exclusion of others.

During the past few years the writer has been No. 2856 , VOL. I I 4$]$ working at improvements in the construction of transmitters and receivers based on the principle of selective tuning, which it is hoped may find a useful field of application in an improved system of depth sounding for navigation purposes.

Louis V. KING.

McGill University, June ${ }_{5}$.

\section{Study of Explosions.}

Sir Oliver Lodge, in Nature of July 5 , p. Io, suggests that the methods of producing the "Big Bangs," which have previously been used, may not be the most effective for the purpose.

While on service in France with the Artillery, it appeared evident to me that the noises with the greatest " carrying power" were made by the gun discharges, and not by detonations of high explosive shells.

The battery with which I was at the time was a 6 -in. howitzer battery, and I noticed that the detonations of our own shells, although visually observed from an O.P. at 2000 or 3000 yards range, were often inaudible; whereas an enemy gun or howitzer at the same order of distance was always distinctly heard.

The noise of the great bombardment near Ypres in 1917, which was clearly heard from the South Downs in England, always seemed to me to be that due to the guns themselves, and quite unlike the characteristic "c-r-r-rumps" of H.E. shell detonations.

It seems possible that the detonation of a high explosive must produce an air wave of a very steep wave front, which may be damped out by the internal friction of the air particles more rapidly than the slower rise and fall of pressure produced by the combustion of the propellent type of explosive.

It is to be hoped that Sir Oliver Lodge's suggestion that in a future trial a charge of gunpowder or cordite should be exploded, in some form of container if necessary, at a considerable height from the ground, will be adopted.

Hadley House, Pangbourne, Berkshire.

IN view of the recent attempts to utilize surplus munitions of war in the investigation of the propagation of sound in the atmosphere, it may be worth while to direct attention once more to the opportunity that explosions afford for investigating the propagation of seismic waves in the upper layers of the earth's crust. In the Oppau explosion 4000 tons of explosive produced a wave that was recorded by a seismograph at a distance of $365 \mathrm{~km}$. This was a surface explosion. The momenta communicated to the air and the earth by the shock must have been equal, and therefore the amounts of energy that went into the air and the earth must have been in the ratio of the velocities; thus much less than a thousandth of the energy can have gone into the seismic wave. If, however, the explosive is buried deep in the ground, nearly all the energy will go into the earth. Thus a wave of intensity greater than that produced by the Oppau explosion could be produced by firing 4 tons of explosive underground. Further, timing could be made specially easy by having the explosion in wireless communication with the observatories, thus eliminating the uncertainty of the time at the focus.

St. John's College, Cambridge.
HAROLD JEFFREYS. 